\title{
Sociology and Animal Studies: Human Responses to Animal Loss in Times of Disaster
}

\author{
Joseph Ching Velasco \\ De La Salle University, Manila \\ josephchingvelasco@gmail.com, ORCID ID: 0000-0002-7098-8216
}

\begin{abstract}
A number of attempts have been made to include animals in explorations in the humanities and social sciences. This is a response to the gap where animals are much-neglected entities in the said disciplines. There have been debates pertaining to the inclusion of animals in scholarly discourses in the field of sociology. Notably, human exceptionalism has been one of the key ideological drivers which prevent a more inclusive consideration of animals in the study of our social world. The anthropocentric view of the world and society has put the needs and status of humans above all other animals. This line of thinking has implications on how humanity relates and interacts with animals in a broader context. In times of crisis, humans relegate animals as conveniently expendable or an inconvenient afterthought, which easily leads to instances of animal abandonment and even abuse. However, there has been a collective shift in the way acts of animal abandonment are perceived on social media. This article examined the responses on social media pertaining to animal abandonment during the onslaught of typhoon Vamco in the Philippines in 2020. More specifically, two themes were analyzed: outrage against negligence and compassionate treatment of animals. While this article looks specifically at the abandonment of animals, the project invites further reflection on the notions of environmental ethics and the species boundary.
\end{abstract}

\section{Keywords}

Animal Loss, Animal Abandonment, Animal Liberation, Typhoon Vamco, PAWS, Sociology of Animals

\section{Introduction}

In November 2020, Metro Manila experienced the devastation of Vamco, the $21^{\text {st }}$ tropical cyclone to ravage the Philippines for the said year. Locally, typhoon Vamco was named Ulysses. It lashed out in the islands of Luzon and unleashed severe rainfall and flooding that led to the displacement of people. IFRC (2020) notes that 19.1 million individuals were affected by the disaster with 20,000 people needing assistance particularly in Metro Manila, Quezon, and Rizal provinces. The National Disaster Risk Reduction and Management Council of the Philippines (2020) recorded 196 incidents of flooding, 73 casualties, and 19 missing persons as a consequence of the typhoon. Aside from 
bearing the brunt of the typhoon, the Philippines is simultaneously experiencing one of the most challenging public health emergencies and life disruptions due to the COVID-19 pandemic (Bernardo \& Mendoza, 2020).

Individuals were evacuated to prevent further loss of life from the onslaught of the typhoon. However, some families have unfortunately abandoned their companion animals. Media reports have shown animals stuck in rooftops or swimming in raging floodwaters. Fortunately, some companion animals were later reunited with their owners. However, there were instances when animals were left in cages or leashed as the floodwaters gradually consumed cities. Although animal neglect is a criminal offense in the Philippines, it is undeniable that in times of crises and disasters, animal abandonment is quite prevalent. Companion animals, for the most part, are seen as an integral part of human society. However, during difficult times, they are often overlooked and considered as risks (Chadwin, 2017). For the most part, they are considered afterthoughts and rendered invisible in disaster response initiatives.

The Philippine Animals Welfare Society (PAWS) issued a reminder to the public to "give animals a fighting chance during disasters" (ABSCBN News, 2020). When PAWS returned to Provident Village in Marikina City, they discovered corpses of animals that were still chained or caged. These companion animals were condemned to death when they were abandoned by their owners. Heath and Linnabury (2015) call this phenomenon "pet evacuation failure" which is a form of abandonment. Therefore, this project unpacks the collective response of individuals on pet abandonment in times of disaster. It also briefly lays out considerations for the advancement of sociological explorations of human-animal entanglements. A qualitative examination of the social media responses to PAWS' documentation of companion animal death was conducted. More specifically, this project parses through the categories of response to companion pet loss mediated through social media in the context of Typhoon Vamco.

\section{Animals in Society and Sociology: Rethinking the Human-Animal Connection}

Bryant (1979) raised the alarm on how the social sciences, particularly sociology, have failed to "address the zoological component in human interaction and attendant social system" (p. 399). He then makes a compelling case for the concept of the zoological connection or "the influence of animals, or their import for, our social behavior, our relationship with other humans, and the directions which our social enterprise often takes" (p. 399). Sociology generally thus remained an anthropocentric area of study with the purpose of elevating the "status, needs and importance of humans above all other animals" (Grauerholz et al., 2020, p. 121). This particular disciplinal stance is driven by the position taken by George Herbert Mead. Alger and Alger (2003) further clarify:

Mead defined the unique social capacities of humans by denying these same capacities to nonhuman animals. Humans are conscious and can choose courses of action, animals are 
not conscious and operate only on instinct; humans can communicate with symbols, animals cannot; humans have language and create culture, animals have neither language nor culture; and animals live only the present while humans have a sense of both past and future. (p. 69)

The superiority of humans over animals is at the heart of "human exceptionalism." Carter and Charles (2018) argue:

Human exceptionalism refers to the idea that the human species is exempt from natural constraints (primarily because of its scientific and technological achievements) and is evolutionarily unique (because of its capacity for language and the capacities for meaning making and cultural development that are emergent from this). (p.81)

Human exceptionalism is advanced in Mead's delimitation of what ought to be sociological. Particularly, he asserted that animals are not part of the discipline of sociology because they lack the capacity for language, imagination, and perception (Peggs, 2012). Furthermore, he posits that only humans are capable of language and culture (Grauherholz et al., 2020). Any semblance of purpose or even cognition from animals, in Mead's perspective, is a "foolish projection on our part, which we would abandon once we really understood animals" (Irvine, 2008, p. 1958).

The alleged uniqueness of humans, therefore, is considered the primary demarcation of what ought to be sociological. This line of thinking has far-reaching consequences, the most critical of which is, the erasure of animals from the function of society and the intensification of speciesism. Irvine (2008) succinctly captures this glaring gap in our understanding of the role of animals in human life. She reveals, "in light of the tremendous influence of animals on culture and their numerous roles in society, their omission from sociological study has given us an incomplete picture of the social world" (Irvine, 2008, p. 1966). Furthermore, there is resistance from sociology to consider animals as an oppressed group as it purportedly diminishes the notion of oppression (Carter \& Charles, 2018). Speciesism, just like sexism and racism, is a form of oppression and is also institutionalized. It is "the exaltation of humans (their rights, needs, wants, and interests) over all other species of animals" (Taylor \& Fraser, 2019, p. 344) or the belief that humans are of higher moral worth than animals (Wilks et al., 2019). Singer (2002) argues that speciesism is "prejudice or attitude of bias in favor of the interests of members of one's own species and against those of members of other species" (p. 6).

Several attempts have been made to include animals in sociological explorations (Carter $\&$ Charles, 2018). This is a response to the scholarly chasm where animals are much-neglected entities in sociology (Peggs, 2012) and the omission of animals in the discipline (Irvine, 2008). Why are animals a part and parcel of our social world? Carter and Charles (2018) provide the following reasons. First, contrary to Mead's assertions, animals do have a sense of self and the relationship of human and animals are depicted as a form of intersubjectivity. Human-animal relations are 
influenced by changing social relations. Second, it is asserted that sociology is imbued with a moral and political duty to attend to animals in the same way it entangles itself with different forms of oppressed and vulnerable groups. Lastly, animals do occupy a position in human social life, that is, "societies would not have taken the form that they do, had it not been for human connections with other animals" (Carter \& Charles, 2018, p. 86). Animals, ultimately, are participants in the formation of the selfhood of humans (Jakoby, 2015).

Animals do have agency, Jakoby (2015) argues that animals possess the following qualities: agency, affectivity, coherence, and a history of selfhood. With more insights gathered on the conditions of animals, evidence of thought, culture, and even emotions have become more ostensible (Irvine, 2008). When it comes to companion animals, their constant interaction with humans possibly leads to their anthropomorphism, that is, an ascription of human attributes (Veevers, 1985). Nevertheless, much is needed to be done to achieve a fuller understanding of the human-animal connection through the lenses of the social sciences. On a more pragmatic level, Peter Singer (2002) in his work titled Animal Liberation, argues that we must "bring nonhuman animals within our sphere of moral concern and cease to treat their lives as expendable for whatever trivial purposes we may have" (p. 20).
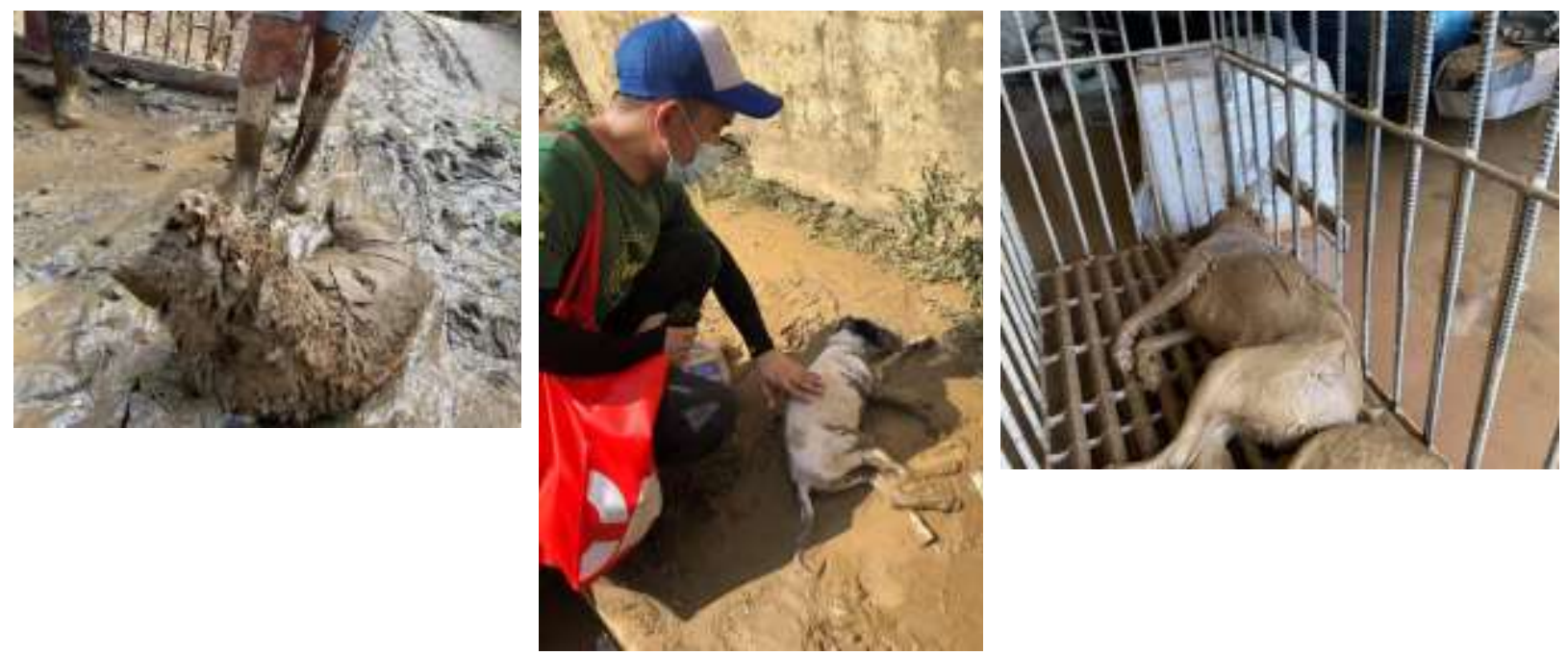

Figure 1: Images of dead animals in Provident Village in Marikina City, Philippines shared by PAWS Note. These images were sourced from the Facebook page of Philippine Animal Welfare Society

\section{Animal Loss in the Midst of Typhoon Vamco in the Philippines}

The Philippine Animal Welfare Society (PAWS), a non-profit organization dedicated to the humane treatment of animals, conducted rescue operations at Provident Village in Marikina City, which was severely affected by the typhoon. On November 13, 2020, the Philippine Animal Welfare Society (PAWS), through its Facebook page, shared a series of harrowing images of animal death. 
Although a few animals were rescued, some were unable to escape the rising floodwaters because they were chained or caged. When these animals were left shackled, they were inevitably condemned to their untimely demise. Whilst the owners of these animals were preoccupied with saving themselves, they, unfortunately, overlooked that their companion animals are solely dependent on their care and attention.

Figure 1 shows some of the distressing images that were publicly shared by the organization. Some of the animals that were found dead were still chained or caged, most were covered by mud as a result of the flooding. These animals, as shown in the Figure, did not even get the chance to save themselves; it was impossible because of the physical restraints. While this incident can be attributed to the failure of the owners to look after their companion animals, it also reveals a host of structural and societal negligence. Darroch and Adamson (2016) clarify that "companion animals have often been treated as an afterthought, or ignored, by those involved in planning for and responding to disasters" (p. 100).

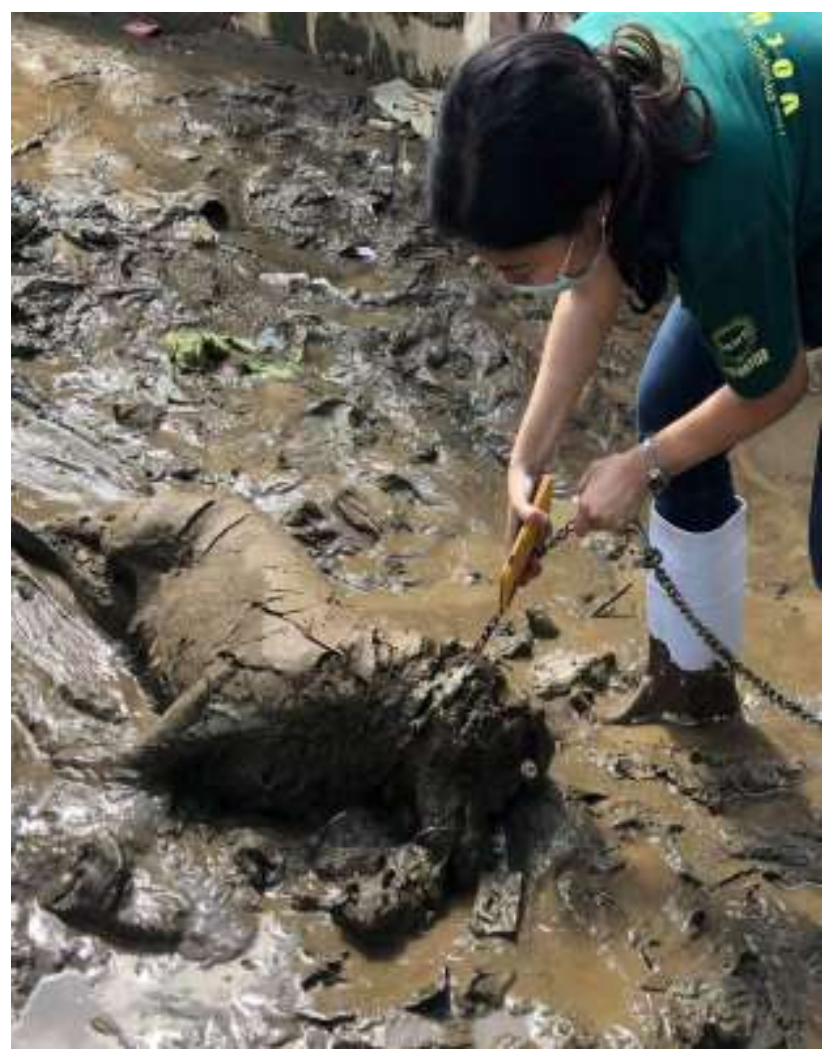

Figure 2: The executive director of PAWS examining the collar of dead chained dog

Note. This image was sourced from the Facebook page of Philippine Animal Welfare Society.

Figure 2 shows the executive director of the PAWS examining the corpse of a chained dog unable to survive the deluge. The post that PAWS shared on their rescue operations in Provident Village in Marikina City garnered approximately 63,000 reactions and 46,000 shares. Aside from 
gaining a significant number of reactions, it also amassed thousands of comments. The post has a corresponding text which reads:

Give a fighting change during disasters. Unchain your dogs and unlock their cages if you cannot evacuate with them during times of emergencies or disaster. PAWS found these poor dogs either chained or locked inside a cage, giving them no opportunity for survival during the flooding brought by super typhoon Ulysses. The PAWS Disaster Response Team is currently in Provident Village, Marikina (a heavily flooded community) to extend relief to pet owners and their pets affected by the storm. (PAWS, 2020)

This specific post is the focal point of this paper, that is, the analysis of the comments through computer-assisted qualitative data analysis software (CAQDAS). On November 14, 2020, NVIVO's NCapture was used to systematically collect and compile the comments for this specific post. Overall, 5,251 comments were successfully collected and subsequently analyzed, which forms the dataset of this inquiry.

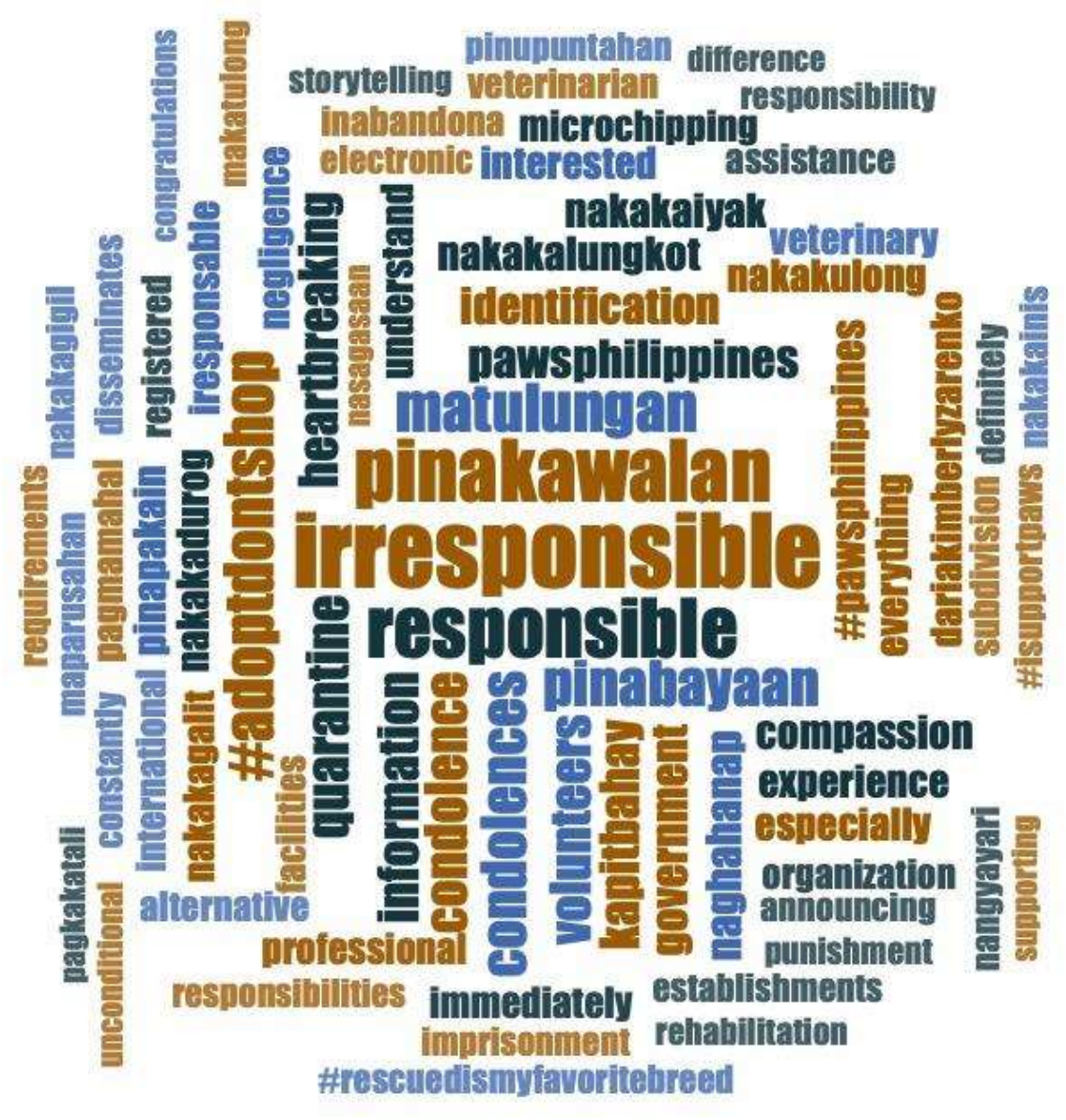

Figure 3: Frequently occurring words among the comments vis-à-vis animal loss

A word cloud was produced based on the comments that were collected, which is shown in Figure 3. A word cloud transforms textual data into visual form in order to get a better grasp of 
the commonly occurring words in the dataset. The most frequent terms that occurred in the dataset are the following: irresponsible with 311 instances, pinakawalan (to set free) with 237 instances, responsible with 222 instances, matulungan (to be helped) with 157 instances, and pinabayaan (neglected) with 138 instances. A deeper examination of these highly occurring terms highlights the dominant responses toward animal deaths.

Table 1: Frequently occurring words and selected contexts

\begin{tabular}{ll} 
Word & \multicolumn{1}{c}{ Data Extract } \\
\hline & $\begin{array}{l}\text { It's never an excuse to maltreat dogs! I am a fur-mom to } 4 \text { dogs, I never tied them. They } \\
\text { roam freely inside my house, and they do their business in my fenced backyard. The } \\
\text { only time they are leashed is when we walk in the park. There are a lot of irresponsible } \\
\text { dog owners in the Philippines and that's the truth! }\end{array}$ \\
\cline { 2 - 2 }
\end{tabular}

The only difference between man and lower form of animals is the capacity to think. But as to pain and survival there is no difference. These people are irresponsible by leaving their pets without giving them the chance of surviving.

Nakakaawa matapos maging guard dogs ay di naalala pakawalan ang mga aso. Sana ng mag umpisa na pumasok ang baha ay pinakawalan na nila ang mga aso kung hindi nila kayang isama sa paglikas.

[This is pitiful. After being guard dogs, the owners forgot to set them free. Before the flooding started, the owners should have set them free if they cannot take them to a safe location.]

pinakawalan

(to set free)

responsible
This is so heartbreaking to see. I know yung may ari nag panic or siniguro mag survive. Pero sana hindi kinalimutan na responsible mo yan as an owner. Kasi gusto rin ng mga hayop na magsurvive, gusto rin nilang mabuhay. Kahit pinakawalan nalang sana marunong naman sana silang lumangoy at may siguradong magkakita at makarescue sa kanila. Hindi yung ganito wala silang kalaban-laban.

[This is heartbreaking to see. I know that the owners panicked or ensured their own survival. However, they should have not forgotten to be responsible pet owners. The animals want to survive, they want to live. The least that could have been done is to set them free because animals know how to swim. Some rescuers later on and spot the animals. Their owners should have not left them for dead without a fighting chance.]

Be responsible to take good care of your furbabies. They have their own life too! I'm so sad for them.

Responsible pet ownership... If you can't give them a happy life, don't take them. Saving your lives and leaving them to suffer is just cruel. This is so heartbreaking. 
Nakaka-awa sila, hindi man lang nabigyan ng chance to survive. Kung hindi man sila matulungan ng kanilang pet owner na isama sa paglikas, sana pinakawalan na sila. Baka kahit papaano naka survive pa sila.

[What happened to the animals is such a pity, they weren't given a chance to survive. If the owners weren't available to help the animals, they should have at least set them matulungan (to be helped) free. The animals might have survived.]

Ang sa akin lang kung hindi kayang matulungan ng ating mga barangay ay sana tayong mga pet owners magtatag ng sariling pet rescue center... Kapag ganitong kalamidad ay tayo na ang umaksyon.

[In my opinion, if the government officials are unable to assist during calamities; we as citizens should establish pet rescue centers. In times of crisis, we should be the ones to take action.]

Grabe naman, may tali pala. Kawawa yung aso basta na lang pinabayaan.

[This is appalling, they were still chained. The dogs were simply neglected]

pinabayaan

(neglected)
Pinabayaan lang sila na nakatali, waiting for their death. I can't imagine yung fear na naramdaman nila trying to get away.

[They were neglected by being chain and waiting for their death. I can't imagine the fear that they experienced when they were trying to get away.]

Note. Some data excerpts in this table were edited for clarity.

Based on the data excerpts in Table 1, there are two dominant sentiments in relation to instances of animal abandonment during the onslaught of Typhoon Vamco. The first dominant theme is outrage against the negligence of pet owners who abandoned their companion animals. The discourse primarily revolves around the irresponsibility of the pet owners in attending to the safety of their dogs. More specifically, the comments highlight the issue of not including the animals in the pet owner's evacuation plans or setting them free from being chained or caged. The animals were ultimately pinabayaan (neglected). The owners could have at least set them free or pinakawalan to give them a fighting chance to survive.

Another prevailing theme in the dataset is the compassionate treatment of animals. This is primarily articulated through calls for helping the animals in times of crisis. The term matulungan (to be helped) highlights this specific aspect, that is, citizens should also be part of the solution in taking care of the animals. Abandoning the animals is a form of abuse, however, this behavior occurs often. Chadwin (2017) clarifies that "companion animals are an integral part of human society; but when disaster strikes, evacuation and sheltering of companions animals are often overlooked" (p. 1413). 


\section{Conclusion and Future Directions}

This article highlights the gap in the study of animals in the context of the social sciences. As it currently stands, the dominance of human exceptionalism has prevented a more inclusive recognition of animals as part of our social world. This also influences the everyday treatment of animals and, subsequently, the different forms of oppression that they are subjected to. Irvine (2008) points out that "concern for animals does not imply the lack of concern for humans," however "a lack of concern for animals often comes with disrespect for other people" (p. 1966). I assert that animals do occupy a social position and are deeply involved in social relations; hence they deserve further scholarly attention. Sociology as a discipline is particularly ironic because of its eagerness to include the plight of every human minority yet it resists the consideration of the plight of animals (Arluke, 2003).

While this article looks into the plight of animals, it also brings into fore the exigencies of human behavior in relation to other beings. What transpired during Typhoon Vamco is an example of how animals are neglected in society. It underscores the socio-structural failures in the care of companion animals in times of crisis. Humans relegate animals as conveniently expendable or an inconvenient afterthought, which easily led to instances of animal neglect. However, there seems to have been a collective shift in the way acts of animal abandonment are perceived on social media. There is a palpable sense of outrage against negligence and further calls for compassionate treatment of animals. In looking into the plight of animals, I echo Peter Singer's argument that "we have to speak up on behalf of those who cannot speak for themselves (Singer, 2002, p. xxiii)." Animal welfare is a public good and better treatment of animals is at the heart of a more compassionate society.

\section{References}

ABSCBN News. (2020). PAWS: If you can't evacuate pets in calamity, at least unchain them. https://news.abs-cbn.com/news/11/13/20/paws-if-you-cant-evacuate-pets-in-calamity-at-leastunchain-them

Arluke, A. (2003). Ethnozoology and the future of sociology. International Journal of Sociology and Social Policy, 23(3), 26-45. https://doi.org/10.1108/01443330310790246

Alger, J. M. and Alger., S. F. (2003). Drawing the line between humans and animals: An examination of introductory sociology textbooks. The International Journal of Sociology and Social Policy, 23(3), 69-https://doi.org/10.1108/01443330310790264

Bernardo, A. B., \& Mendoza, N. B. (2020). Measuring hope during the COVID-19 outbreak in the Philippines: development and validation of the state locus-of-Hope scale short form in Filipino. Current Psychology, 1-10.

Bryant, C. D. (1979). The zoological connection: Animal-related human behavior. Social Forces, 58(2), 399421. https://doi.org/10.1093/sf/58.2.399

Carter, B., \& Charles, N. (2018). The animal challenge to sociology. European Journal of Social Theory, 21(1), 79-97. https://doi.org/10.1177/1368431016681305 
10| Rupkatha Journal, Vol. 13, No. 3, 2021

Chadwin, R. (2017). Evacuation of pets during disasters: a public health intervention to increase resilience. American Journal of Public Health, 107(9), 1413-1417. https://doi.org/10.2105/AJPH.2017.303877

Darroch, J., \& Adamson, C. (2016). Companion animals and disasters: The role of human services organisations. Aotearoa New Zealand Social Work, 28(4), 100-108.

Grauerholz, L., Weinzimmer, J., Kidder, E. N., \& Owens Duffy, N. (2020). Teaching about Animals: Incorporating Nonhuman Animals into Sociology Classrooms. Teaching Sociology, 48(2), 120-139. https://doi.org/10.1177/0092055X20906563

Heath, S. E., \& Linnabary, R. D. (2015). Challenges of managing animals in disasters in the US. Animals, 5(2), 173-192. https://doi.org/10.3390/ani5020173

IFRC. (2020). Emergency plan of action (EPoA) Philippines: Typhoon Vamco. https://reliefweb.int/report/philippines/philippines-typhoon-vamco-emergency-plan-actionepoa-dref-operation-n-mdrph042

Irvine, L. (2008). Animals and sociology. Sociology Compass, 2(6), 1954-1971. https://doi.org/10.1111/j.1751-9020.2008.00163.x

Jakoby, N. R. (2015). The self and significant others: Toward a sociology of loss. Illness, Crisis \& Loss, 23(2), 129-174. https://doi.org/10.1177/1054137315575843

PAWS (2020). Give animals a fighting chance during disasters. https://www.facebook.com/pawsphilippines/posts/3497169183662035

Peggs, K. (2012). Animals and Sociology. Springer.

Singer, P. (2002). Animal Liberation: The Definitive Classic of the Animal Movement. Ecco.

Taylor, N., \& Fraser, H. (2019). Resisting sexism and speciesism in the social sciences: Using feminist, species-inclusive, visual methods to value the work of women and (other) animals. Gender, Work \& Organization, 26(3), 343-357. https://doi.org/10.1111/gwao.12246

The National Disaster Risk Reduction and Management Council of the Philippines. (2020). Preparedness measures and effects for Typhoon "Ulysses" (I.N. Vamco). https://ndrrmc.gov.ph/attachments/article/4138/SitRep no 29 re TY Ulysses as of 13JAN2021.pd f

Veevers, J. E. (1985). The social meanings of pets: Alternative roles for companion animals. Marriage \& Family Review, 8(3-4), 11-30. https://doi.org/10.1300/J002v08n03 03

Wilks, M., Phillips, C. J., Fielding, K., \& Hornsey, M. J. (2019). Testing potential psychological predictors of attitudes towards cultured meat. Appetite, 136, 137-145. https://doi.org/10.1016/j.appet.2019.01.027

Joseph Ching Velasco, Ph.D. is a faculty member of the Department of Political Science and current managing editor and former Editor-in-Chief of the Asia-Pacific Social Science Review based in De La Salle University, Manila. He is currently pursuing further studies in international relations and public policy at the University of Macau. His works have appeared in journals such as Asian Ethnicity, Kritika Kultura, and Pertanika Journal of Social Sciences and Humanities. His research interests include Chinese Filipinos, Sino-Philippine Relations, Work Ethic, and Burnout. 